\title{
Spatial analysis of risk factors for transmission of the Barmah Forest virus in Queensland, Australia
}

\author{
Suchithra Naish ${ }^{1}$, Kerrie Mengersen², Shilu Tong ${ }^{1}$ \\ ${ }^{1}$ School of Public Health and Social Work and Institute of Health and Biomedical Innovation, Queensland \\ University of Technology, Queensland, Australia; ${ }^{2}$ Mathematical Sciences, Queensland University of \\ Technology, Queensland, Australia
}

\begin{abstract}
Barmah Forest virus (BFV) disease is the second most common mosquito-borne disease in Australia but few data are available on the risk factors. We assessed the impact of spatial climatic, socioeconomic and ecological factors on the transmission of BFV disease in Queensland, Australia, using spatial regression. All our analyses indicate that spatial lag models provide a superior fit to the data compared to spatial error and ordinary least square models. The residuals of the spatial lag models were found to be uncorrelated, indicating that the models adequately account for spatial and temporal autocorrelation. Our results revealed that minimum temperature, distance from coast and low tide were negatively and rainfall was positively associated with BFV disease in coastal areas, whereas minimum temperature and high tide were negatively and rainfall was positively associated with BFV disease (all P-value $<0.05$ ). The study demonstrates that BFV disease is more densely distributed in coastal areas and is influenced by climatic and ecological factors. The spatial analytical approach used in this study may have ramifications in the planning and implementation of BFV disease prevention and control programmes.
\end{abstract}

Keywords: Barmah Forest virus, geographical information system, spatial regression, risk factors, Australia.

\section{Introduction}

Barmah Forest virus (BFV) disease is a mosquitoborne disease transmitted primarily by Aedes and Culex vector species (Russell, 1995). Hot spots of BFV disease are mainly found in coastal regions in Australia (Naish et al., 2011b), where the expansion of urban populations, tropical and sub-tropical temperatures and precipitation create ideal habitats for vector proliferation and consequent spread of the virus (Queensland Health, 2012). Since 1992, the recorded number of laboratory-confirmed BFV cases in Australia has been highest in the State of Queensland (Queensland Health, 2012). Large outbreaks occurred in 2003 and 2008, with 869 and 1,243 cases (incidence rates of 22.3 and 28.1 per 100,000 people), respectively in Queensland (Queensland Health, 2009).

BFV disease is complex and the transmission dynamics of the disease are affected by biotic (e.g. abundance and distribution of mosquitoes and suscep-

\footnotetext{
Corresponding author:

Suchithra Naish

School of Public Health and Social Work and

Institute of Health and Biomedical Innovation

Queensland University of Technology

Kelvin Grove, Brisbane, Queensland 4059, Australia

Tel. +61 73138 3996; Fax: +61 731383369

E-mail:s.naish@qut.edu.au
}

tible vertebrate hosts) and abiotic factors (e.g. temperature and rainfall) (Mc Michael et al., 2008; Russell, 2009). Previous studies have shown that temperature and rainfall, reservoir host, geography and population demographics are associated with BFV disease epidemics (Lindsay and Mackenzie, 1998; Mackenzie et al., 2000; McMichael et al., 2003). Some other studies have revealed that human related factors (e.g. behaviour and immunity) are also involved in the disease distribution (McBride, 2008; Russell, 2009). However, the exact roles of each of these factors are not yet fully understood (Russell, 2009). Recently, few studies have explored the relationship between climate variability and the transmission of BFV disease in coastal Queensland in Australia (Naish et al., 2006, 2009).

Recently, the understanding of the transmission dynamics of BFV disease in Queensland has expanded through the use of geographical information system (GIS) tools. However, most of the previous studies have only employed GIS for descriptive analyses (Quinn et al., 2005; Tong et al., 2005; Pelecanos et al., 2011). Few empirical studies have explored the disease risk using spatial pattern analysis, which generates more precise information about high-risk areas of disease transmission (Naish et al., 2011a, 2011b). As extensively discussed in the geography, spatial statistics and spatial epidemiology, ignoring possible spatial effects (such as spatial dependence and heterogeneity) in data analysis 
might lead to unreliable estimates and potentially misleading inferences (Cliff and Ord, 1973; Anselin and Getis, 1992; Bailey and Gatrell, 1995; Anselin and Bera, 1998; Griffith, 2006; Yu and Wei, 2008).

Methods for analysing predictors of disease outbreaks over space and time have advanced substantially over the last decade. The change in approach has been warranted by the fact that traditional application of ordinary least square (OLS) regression for the analysis of outbreaks assumes that there is no spatial dependence/clustering. As evidenced by a number of studies (Quinn et al., 2005; Naish et al., 2011a; Pelecanos et al., 2011), this assumption is not in accord with the epidemiologic characteristics of BFV disease, because BFV incidence in a specified spatial unit (such as local government area (LGA) or statistical local area (SLA)) is likely to be dependent on location. In other words, units that are close to each other are more likely to have similar BFV incidence rates, depending on the degree of interaction between the populations in neighbouring units and on variations in climatic, socioeconomic and ecological factors that influence BFV disease (Quinn et al., 2005; Naish et al., 2011a; Pelecanos et al., 2011).

With the recent advances and improvements in GIS applications and the ensuing infusion of other associated statistical packages into geographical software, models have been developed to account for spatial autocorrelation (Cliff and Ord, 1973; Anselin and Getis, 1992, 1998; Bailey and Gatrell, 1995; Griffith, 2006; Yu and Wei, 2008). The application of these techniques specifically for studies of mosquito-borne diseases has attracted increasing attention ( $\mathrm{Li}$ et al., 2008; Feng et al.,
2011; Impoinvil et al., 2011). A second issue associated with spatial regression analyses is spatial heterogeneity i.e. non-stationarity of model parameters as a result of the substantial differences in the variance of the dependent and independent variables across space (Anselin and Bera, 1998). In order to take into account spatial autocorrelation and heterogeneity, this study examined the potential impact of spatial climatic, socioeconomic and ecological factors on BFV transmission in Queensland, using a spatial modelling approach.

\section{Materials and methods}

\section{Study area}

Queensland is the second largest state of Australia by area after Western Australia and is located in the north-east of the country with Brisbane as the capital city (Fig. 1). Queensland covers 1,723,936 km² with approximately $9,800 \mathrm{~km}$ of coastline, including islands. Its population was 4,561,711 on March 31, 2011 (Australian Bureau of Statistic, 2011). The micro-level geographical unit in Australian census data is mesh block. Queensland consists of 60,758 spatial mesh blocks (Australian Bureau of Statistics, 2010), with most residential mesh blocks containing 30-60 dwellings. It has a tropical and sub-tropical climate with average temperatures of $25^{\circ} \mathrm{C}$ in summer and $15^{\circ} \mathrm{C}$ in winter and rainfall varies regionally and seasonally. However, most of the state recorded over $50 \%$ of the rainfall during summer with average rainfall varying from $<150 \mathrm{~mm}$ in southwest region to $>4000 \mathrm{~mm}$ on the northern coast.

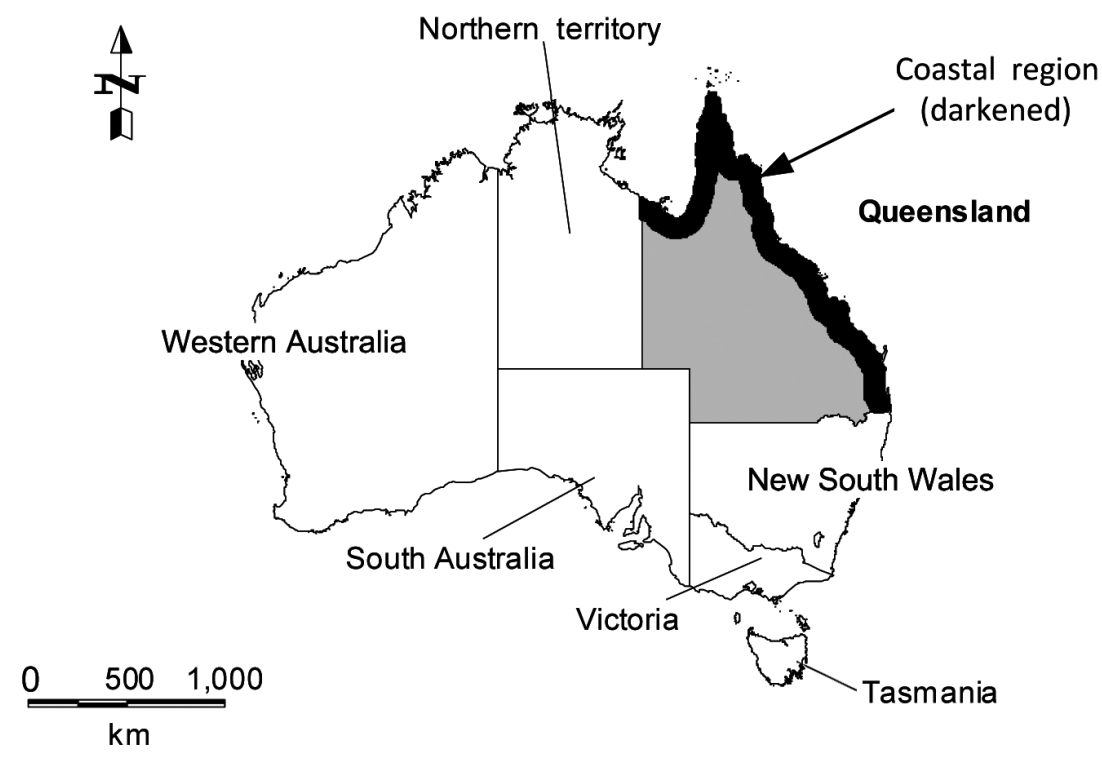

Fig. 1. Map of Australia with the study area highlighted using dark and light shades. 


\section{Ethics statement}

The study was approved by the Human Research Ethical Committee of the Queensland University of Technology (Brisbane, Australia).

\section{Data collection}

\section{BFV data}

A computerised dataset on daily notified cases of BFV disease was obtained from the Communicable Diseases Division, Queensland Health for the years 2000 to 2008. Detailed descriptions of data features and geocoding can be found elsewhere (Naish et al., 2011b).

\section{Explanatory variables}

To facilitate risk profiling, a multiple-factor database including climatic, sociodemographic and ecological variables was developed for analysis. The following aggregated variables were included: mean maximum annual temperature, mean minimum annual temperature, total annual rainfall, mean annual high tide, mean annual low tide, mean annual SEIFA index, mesh block population and total area of each wetland type.

Grid climate data from across Queensland with complete maximum temperature, minimum temperature and rainfall records for the same period were obtained from Australian Bureau of Meteorology (2011). Mesh block population data were obtained from Australian Bureau of Statistics (2010). The data included the number of dwellings and the overall population for the latest national census year, i.e. 2006. The mesh block population data were used in the computation of BFV disease incidence rates. Data were entered into a GIS database format. Socioeconomic data (i.e. SEIFA index) were obtained from Australian Bureau of Statistics (2006). Tidal data were obtained from the Queensland Department of Transport and Main Roads (2009); the data included two high and low tide readings per day for each tidal monitoring station across Queensland for the period 2000-2008. Geo-referenced wetland data were obtained from the Queensland Wetlands Programme (2009); these data included areas covered with vegetation and location of mangroves for Queensland. Incidence rates of BFV disease and explanatory variables were converted into polygon data in each grid. MapInfo Professional (2010) incorporated with Vertical Mapper (2010) and Microsoft Excel were used for data management and integration.

\section{Statistical analysis}

\section{Data structure}

It was decided for this study that use of arbitrary boundaries, such as LGAs, SLAs and suburbs, would introduce a dislocation between the location of case data and potential BFV mosquito breeding habitats. Therefore the entire study area was divided into $5 \times 5$ $\mathrm{km}$ grid cells. The data analysis included two different datasets, based on selections of the grid cells. The first dataset included the total area of Queensland consisting of 70,968 grids, and the second included only coastal areas in Queensland (grid cells with centroids located $\leq 100 \mathrm{~km}$ to the coastline) consisting of 14,399 grids (Naish et al., 2012a). Only the grids which were located over mainland were retained (Queensland dataset) and the extraneous grids such as those over islands were discarded $(<0.01 \%)$.

To account for the spatial proximity of the case site and any nearby habitats or variables contributing to the spread of BFV disease, $10 \mathrm{~km}$ circular buffers were developed at the centre of each grid cell (Rushton, 1998). It is noted that these buffers had considerable overlaps with the adjacent grids, and this is done to ensure that potentially important data located in adjacent grids were not excluded from the attributes on any individual grid cell. As an example, case data were likely to be located in suburbs surrounded by houses, while breeding habitats such as wetlands could be in close proximity but outside the cases' grid cell. Thus if the cases' grid cell polygon was only used to extract data from the wetland polygons, important information would be missed and there would be little difference compared to the use of arbitrary boundaries such as SLAs (Naish et al., 2012a). The radius size of the circular buffer was chosen to be $10 \mathrm{~km}$ as this encompasses the environmental conditions which may contribute to the transmission of BFV disease, namely mosquito breeding habitats (Naish et al., 2012a) and BFV mosquito flight range (Whelan, 1997). The 10 $\mathrm{km}$ radius circle was used to extract or calculate a number of variables such as (i) total number of BFV cases; (ii) the proportion of area of each wetland type falling within the circle; (iii) local climate; (iv) local tides; (v) population (from mesh blocks); and (vi) socioeconomic index (SEIFA). A detailed description of coastal dataset can be found elsewhere (Naish et al., 2012a).

In order to evaluate temporal changes, analyses were conducted for the entire period 2000-2008, after which separate analyses were conducted for two sepa- 
rate study periods: an early period comprising data for the years 2000-2004 and a later period comprising remaining data for the years 2005-2008.

Exploratory univariate analyses were conducted for each dependent and explanatory variable for each dataset and for each period. Within each grid, the incidence rate of BFV was calculated as follows:

Incidence rate $=\left|\frac{\text { total number of } B F V \text { cases }}{\text { population }}\right| \times 100,000$

Correlation analyses were performed to assess the associations between incidence rate of BFV disease and explanatory variables. The highly significant $(\mathrm{P}<0.01)$ variables were used in modelling analysis. Collinearity between all possible pairs of explanatory variables was assessed, and if a correlation coefficient of $\geq 0.75$ was observed, the best-fit explanatory variable was retained for model fitting.

Spatial regression modelling and analysis

Spatial regression analyses were conducted to examine significant associations between BFV and explanatory variables for each dataset and each period using GeoDa (Anselin, 2004). Due to the skewed distribution, the dependent variable, BFV disease incidence rate was $\log$ transformed whereas explanatory variables were untransformed in the model. A step-wise backward approach was used to identify the final model. Initially, data were fitted with an ordinary least squares (OLS) regression model which is as follows:

$$
\begin{gathered}
e \sim N(0, \sigma 2) \\
\log (\hat{Y})=\mathrm{X} \beta+e, n
\end{gathered}
$$

where $\hat{Y}$ is the dependent variable, $\mathrm{X}$ is a matrix of observations of explanatory variable, $\beta$ is the regression coefficient and $e$ is an error term. A classical OLS regression analysis overlooks spatial dependence of spatial problems and cannot effectively describe spatial patterns. The diagnostic tests (e.g. Breusch-Pagan and residual plots) were used to determine the presence of spatial dependence (autocorrelation) and heteroskedasticity in the residuals of each model.

We examined two formulations of spatial regression models to account for spatial autocorrelation: a spatial lag model (SLM) and spatial error model (SEM). The SLM includes a spatially lagged dependent variable and allows determination of whether the dependent variable covaries with its geographical neighbours (Anselin, 2004; Ward and Gleditson, 2008). In con- trast, the SEM incorporates an autocorrelation term as an explanatory variable, thus splitting the error term into spatially structured and spatially unstructured terms (Anselin et al., 2006). The SLM can be expressed as:

$$
\log (\hat{Y})=\mathrm{X} \beta+\rho W Y+c
$$

where $\rho$ is the spatial regression coefficient, $W Y$ is the spatially lagged dependent variable and $c$ is the random error term. The SEM can be written as:

$$
\begin{gathered}
\log (\hat{Y})=\mathrm{X} \beta+c \\
c=\lambda W c+\xi
\end{gathered}
$$

where $\lambda$ is the spatial autoregression coefficient, $W$ is the row-standardised spatial weights matrix, $W_{c}$ is the spatially lagged error term, and $\xi$ is the independent error term.

A Moran's I was calculated to check if the residuals of the selected final models for the dataset were spatially correlated (Anselin, 1998; Anselin et al., 2006). The distance weights matrix created by GeoDa was used in this analysis which is acceptable because the data points are systematically spread into a grid and also in this way, every point will have at least one neighbouring point. We ran several models using OLS, SLM and SEM analyses and these were compared to determine the best-fit model based on Akaike Information Criterion (AIC) (Anselin, 2004) and this was considered as the most parsimonious model. All the parameters were significant at the 0.01 probability level.

\section{Results}

\section{Study characteristics}

BFV incidence rates varied by space (Table 1); generally, higher rates were observed in the coastal areas and lower rates in the total area of Queensland. All the variables showed distinct differences for each dataset and for each period. Spearman correlation analyses indicate that the BFV incidence rates were negatively and significantly associated with minimum and maximum temperature, and tides, and positively and significantly associated with rainfall and SEIFA (Table 2).

\section{Regression models}

Table 3 shows the results of each best-fit spatial regression model (OLS, SLM and SEM) for the total area of Queensland for each period. All OLS models 
Table 1. Characteristics of study variables 2000-2008.

\begin{tabular}{|c|c|c|c|c|c|c|c|c|}
\hline \multirow{2}{*}{ Variable } & \multicolumn{4}{|c|}{ Total area } & \multicolumn{4}{|c|}{ Coastal areas } \\
\hline & Mean & SD & Min & $\operatorname{Max}$ & Mean & SD & Min & Max \\
\hline BFV incidence & 5.6 & 272.7 & 0 & 20,000 & 89.8 & 394.5 & 0 & 12,500 \\
\hline Tmin & 16.7 & 2.6 & 8.4 & 24.0 & 18.7 & 2.9 & 10.2 & 24.0 \\
\hline Tmax & 30.6 & 2.2 & 21.5 & 34.1 & 29.9 & 2.7 & 23.2 & 34.1 \\
\hline Rainfall & 47.9 & 29.0 & 10.9 & 269.1 & 86.7 & 33.0 & 41.8 & 269.1 \\
\hline High tide & 0.59 & 1.24 & 0 & 5.30 & 2.9 & 0.90 & 1.30 & 5.30 \\
\hline Low tide & 0.20 & 0.42 & 0 & 1.40 & 1.01 & 0.23 & 0.30 & 1.40 \\
\hline Population & 599 & 9,293 & 0 & 49,936 & 2,632 & 20,311 & 0 & 49,936 \\
\hline SEIFA & 927.1 & 57.7 & 0 & $1,201.7$ & 904.2 & 106.8 & 0 & $1,201.7$ \\
\hline
\end{tabular}

Tmin, minimum temperature; Tmax, maximum temperature.

achieved a multicollinearity number for each of the model (ranging from 10 to 19), much smaller than the typical threshold value of over 30 . However, the regression diagnostics revealed that the data had violated a number of OLS regression assumptions, with the characteristics of non-normality, heteroskedasticity and high spatial autocorrelation (Anselin, 2006). The Moran's I statistic for the OLS residuals ranged from 0.674 to 0.719 (Fig. 2).

The results of each best-fit SLM and SEM suggest that there was a statistically significant, negative association between minimum temperature and BFV incidence rate and a significant positive association between rainfall and BFV incidence rate, after controlling for the other factors in the model (Table 3). The SLM residuals were not spatially correlated. The Moran's I statistic for the SLM residuals ranged from 0.001 to 0.003 (Fig. 2).

Table 4 shows the results of each best-fit OLS, SLM and SEM model for the coastal areas during each period. A multicollinearity number of below 30 was obtained from each of the OLS models (ranging from 7 to 17). However, the regression diagnostics suggested that the data had violated OLS assumptions. All
OLS residuals were spatially autocorrelated and the Moran's I values ranged from 0.687 to 0.701 (Fig. 3).

The results of each best-fit SLM and SEM show that there was a statistically significant, negative association of minimum temperature, low tide and distance to coast, with BFV incidence rate and positive significant association between rainfall and BFV incidence rate. The SLM residuals were analysed by Moran's I scatter plots (Fig. 3). The Moran's $I$ values ranged from 0.001 to 0.005 .

Overall, the Moran's I statistic for spatial lag residuals ranged from 0.001 to 0.005 for coastal areas and total area of Queensland. This indicates that the inclusion of the spatially lagged dependent variable term in the model substantially eliminated the spatial autocorrelation. The spatial lag models also show improved model fit through an increase of $\mathrm{R}^{2}$ values for each model. The maximum temperature and SEIFA were not identified as significant factors in any of the models.

There were noticeable differences in the regression coefficients obtained under the OLS and spatial regression models in both datasets for each period. Since, the SLM has a pseudo- $\mathrm{R}^{2}$ that cannot be directly compared with the $\mathrm{R}^{2}$ of the OLS model, goodness of fit was eval-

Table 2. Spearman correlation coefficients between incidence rates of BFV disease and explanatory variables.

\begin{tabular}{lcccccccc}
\hline \multirow{2}{*}{ Variable } & \multicolumn{3}{c}{ Total Queensland area $(\mathrm{P}<0.01)$} & & \multicolumn{3}{c}{ Coastal Queensland areas $(\mathrm{P}<0.01)$} \\
\cline { 2 - 3 } & $\begin{array}{c}\text { Early period } \\
(2000-2004)\end{array}$ & $\begin{array}{c}\text { Later period } \\
(2005-2008)\end{array}$ & $\begin{array}{c}\text { Total period } \\
(2000-2008)\end{array}$ & & $\begin{array}{c}\text { Early period } \\
(2000-2004)\end{array}$ & $\begin{array}{c}\text { Later period } \\
(2005-2008)\end{array}$ & $\begin{array}{c}\text { Total period } \\
(2000-2008)\end{array}$ \\
\hline Tmin & -0.334 & -0.273 & -0.349 & & -0.088 & -0.076 & -0.034 \\
Tmax & -0.420 & -0.411 & -0.467 & & -0.244 & -0.259 & -0.178 \\
Rainfall & 0.034 & 0.098 & 0.055 & & 0.181 & 0.194 & 0.146 \\
SEIFA & 0.202 & 0.225 & 0.207 & & 0.045 & 0.046 & 0.071 \\
High tide & -0.135 & -0.143 & -0.130 & & 0.238 & 0.242 & 0.191 \\
Low tide & -0.290 & -0.235 & -0.276 & & 0.222 & 0.232 & 0.182
\end{tabular}

Tmin, minimum temperature; Tmax, maximum temperature. 
Table 3. Risk factors of BFV disease transmission for the total area in Queensland.

\begin{tabular}{|c|c|c|c|c|c|c|c|c|c|c|}
\hline \multirow{2}{*}{ Model } & \multirow{2}{*}{ Variable } & \multicolumn{3}{|c|}{ Early period (2000-2004) } & \multicolumn{3}{|c|}{ Later period $(2005-2008)$} & \multicolumn{3}{|c|}{ Total period (2000-2008) } \\
\hline & & $\beta$ & SE & P-value & $\beta$ & SE & P-value & $\beta$ & SE & P-value \\
\hline \multirow[t]{8}{*}{ OLS } & Constant & 1.365 & 0.026 & $<0.001$ & 1.357 & 0.029 & $<0.001$ & 0.346 & 0.015 & $<0.001$ \\
\hline & Distance & -0.000 & 0.000 & $<0.001$ & 0.000 & 0.000 & 0.822 & 0.001 & 0.000 & $<0.001$ \\
\hline & Tmin & -0.089 & 0.002 & $<0.001$ & -0.093 & 0.002 & $<0.001$ & -0.033 & 0.001 & $<0.001$ \\
\hline & Rainfall & 0.006 & 0.0002 & $<0.001$ & 0.0075 & 0.0002 & $<0.001$ & 0.004 & 0.0001 & $<0.001$ \\
\hline & High tide & 0.147 & 0.004 & $<0.001$ & 0.135 & 0.004 & $<0.001$ & 0.052 & 0.002 & $<0.001$ \\
\hline & Adj. $R^{2}$ & 0.080 & & & 0.093 & & & 0.048 & & \\
\hline & LLR & 95,284 & & & 20,211 & & & $-56,227$ & & \\
\hline & AIC & 19,058 & & & $-10,105$ & & & 11,246 & & \\
\hline \multirow[t]{8}{*}{ SLM } & Constant & 0.078 & 0.013 & $<0.001$ & 0.078 & 0.014 & $<0.001$ & 0.022 & 0.008 & 0.005 \\
\hline & Distance & 0.000 & 0.000 & 0.705 & 0.000 & 0.000 & 0.978 & 0.000 & 0.000 & 0.107 \\
\hline & Tmin & -0.005 & 0.001 & $<0.001$ & -0.005 & 0.001 & $<0.001$ & -0.002 & 0.001 & $<0.001$ \\
\hline & Rainfall & 0.000 & 0.0001 & $<0.001$ & 0.001 & 0.0001 & $<0.001$ & 0.0003 & 0.0001 & $<0.001$ \\
\hline & High tide & 0.008 & 0.002 & $<0.001$ & 0.007 & 0.002 & $<0.001$ & 0.003 & 0.002 & 0.002 \\
\hline & Adj. $R^{2}$ & 0.783 & & & 0.787 & & & 0.739 & & \\
\hline & LLR & 51,466 & & & $-56,729$ & & & $-17,197$ & & \\
\hline & AIC & 10,294 & & & 11,352 & & & 34,405 & & \\
\hline \multirow[t]{8}{*}{ SEM } & Constant & 1.149 & 0.207 & $<0.001$ & 1.104 & 0.225 & $<0.001$ & 0.276 & 0.112 & 0.013 \\
\hline & Distance & -0.000 & 0.000 & 0.212 & -0.000 & 0.000 & 0.048 & 0.000 & 0.000 & 0.294 \\
\hline & Tmin & -0.078 & 0.012 & $<0.001$ & -0.064 & 0.013 & $<0.001$ & -0.028 & 0.006 & $<0.001$ \\
\hline & Rainfall & 0.009 & 0.002 & $<0.001$ & 0.006 & 0.002 & $<0.001$ & 0.005 & 0.001 & $<0.001$ \\
\hline & High tide & 0.008 & 0.009 & 0.427 & 0.006 & 0.010 & 0.551 & 0.008 & 0.006 & 0.178 \\
\hline & Adj. $R^{2}$ & 0.783 & & & 0.787 & & & 0.739 & & \\
\hline & LLR & 51,474 & & & $-56,743$ & & & $-1,719$ & & \\
\hline & AIC & 10,295 & & & 11349 & & & 34,408 & & \\
\hline
\end{tabular}

Adj.R², Adjusted coefficient of determination; AIC, Akaike Information Criterion; LLR, Log-likelihood ratio; Tmin, Minimum temperature.
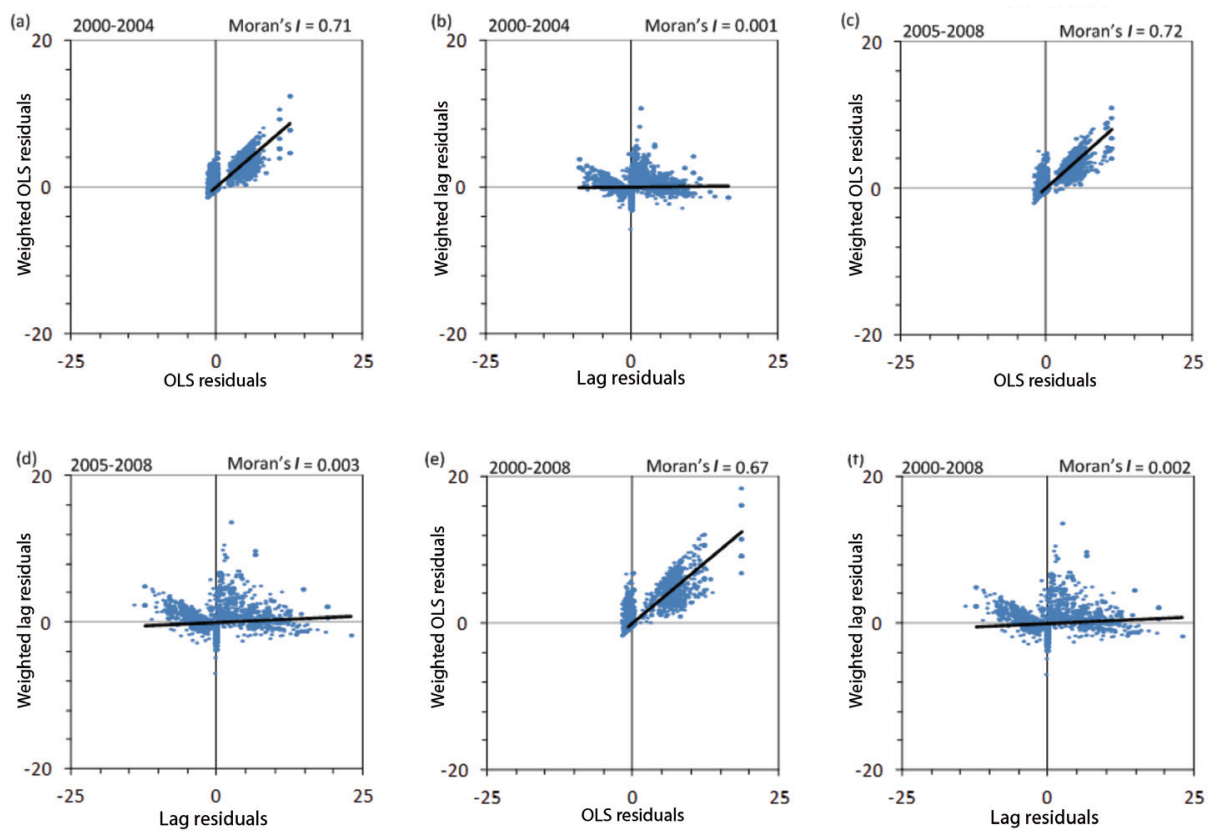

Fig. 2. Moran's I scatter plot for OLS and SLM residuals using the Queensland data. 
Table 4. Risk factors of BFV disease transmission for the coastal areas of Queensland.

\begin{tabular}{|c|c|c|c|c|c|c|c|c|c|c|}
\hline \multirow{2}{*}{ Model } & \multirow{2}{*}{ Variable } & \multicolumn{3}{|c|}{ Early period (2000-2004) } & \multicolumn{3}{|c|}{ Later period (2005-2008) } & \multicolumn{3}{|c|}{ Total period (2000-2008) } \\
\hline & & $\beta$ & SE & P-value & $\beta$ & SE & P-value & $\beta$ & SE & P-value \\
\hline \multirow[t]{8}{*}{ OLS } & Constant & 6.048 & 0.087 & $<0.001$ & 6.499 & 0.100 & $<0.001$ & 8.683 & 0.109 & $<0.001$ \\
\hline & Distance & -0.016 & 0.000 & $<0.001$ & -0.020 & 0.001 & $<0.001$ & -0.023 & 0.001 & $<0.001$ \\
\hline & Tmin & -0.224 & 0.006 & $<0.001$ & -0.245 & 0.006 & $<0.001$ & -0.338 & 0.007 & $<0.001$ \\
\hline & Rainfall & 0.006 & 0.000 & $<0.001$ & 0.008 & 0.000 & $<0.001$ & 0.010 & 0.001 & $<0.001$ \\
\hline & Low tide & -0.973 & 0.064 & $<0.001$ & -0.950 & 0.068 & $<0.001$ & -1.166 & 0.077 & $<0.001$ \\
\hline & Adj. $R^{2}$ & 0.247 & & & 0.243 & & & 0.299 & & \\
\hline & LLR & $-26,047$ & & & $-27,004$ & & & $-28,805$ & & \\
\hline & AIC & 52,103 & & & 54,019 & & & 57,620 & & \\
\hline \multirow[t]{8}{*}{ SLM } & Constant & 0.459 & 0.050 & $<0.001$ & 0.516 & 0.056 & $<0.001$ & 0.685 & 0.064 & $<0.001$ \\
\hline & Distance & -0.001 & 0.000 & $<0.001$ & -0.002 & 0.000 & $<0.001$ & -0.002 & 0.000 & $<0.001$ \\
\hline & Tmin & -0.017 & 0.003 & $<0.001$ & -0.019 & 0.003 & $<0.001$ & -0.027 & 0.004 & $<0.001$ \\
\hline & Rainfall & 0.001 & 0.000 & 0.034 & 0.001 & 0.000 & 0.013 & 0.001 & 0.000 & 0.008 \\
\hline & Low tide & -0.071 & 0.033 & 0.032 & -0.079 & 0.035 & 0.023 & -0.088 & 0.040 & 0.028 \\
\hline & $\operatorname{Adj} . R^{2}$ & 0.799 & & & 0.803 & & & 0.815 & & \\
\hline & LLR & $-17,986$ & & & $-18,718$ & & & $-20,641$ & & \\
\hline & AIC & 35,984 & & & 37,448 & & & 41,293 & & \\
\hline \multirow[t]{8}{*}{ SEM } & Constant & 5.410 & 0.570 & $<0.001$ & 5.392 & 0.618 & $<0.001$ & 7.662 & 0.680 & $<0.001$ \\
\hline & Distance & -0.012 & 0.002 & $<0.001$ & -0.016 & 0.003 & $<0.001$ & -0.019 & 0.003 & $<0.001$ \\
\hline & Tmin & -0.268 & 0.035 & $<0.001$ & -0.228 & 0.034 & $<0.001$ & -0.357 & 0.040 & $<0.001$ \\
\hline & Rainfall & 0.010 & 0.003 & 0.002 & 0.006 & 0.003 & 0.029 & 0.010 & 0.003 & 0.003 \\
\hline & Low tide & -0.009 & 0.224 & 0.969 & -0.172 & 0.222 & 0.439 & -0.036 & 0.272 & 0.894 \\
\hline & Adj. $R^{2}$ & 0.799 & & & 0.803 & & & 0.815 & & \\
\hline & LLR & $-17,991$ & & & $-18,731$ & & & $-20,649$ & & \\
\hline & AIC & 35,993 & & & 37,472 & & & 41,308 & & \\
\hline
\end{tabular}

Adj.R², Adjusted coefficient of determination; AIC, Akaike Information Criterion; LLR, Log-likelihood ratio; Tmin, Minimum temperature.
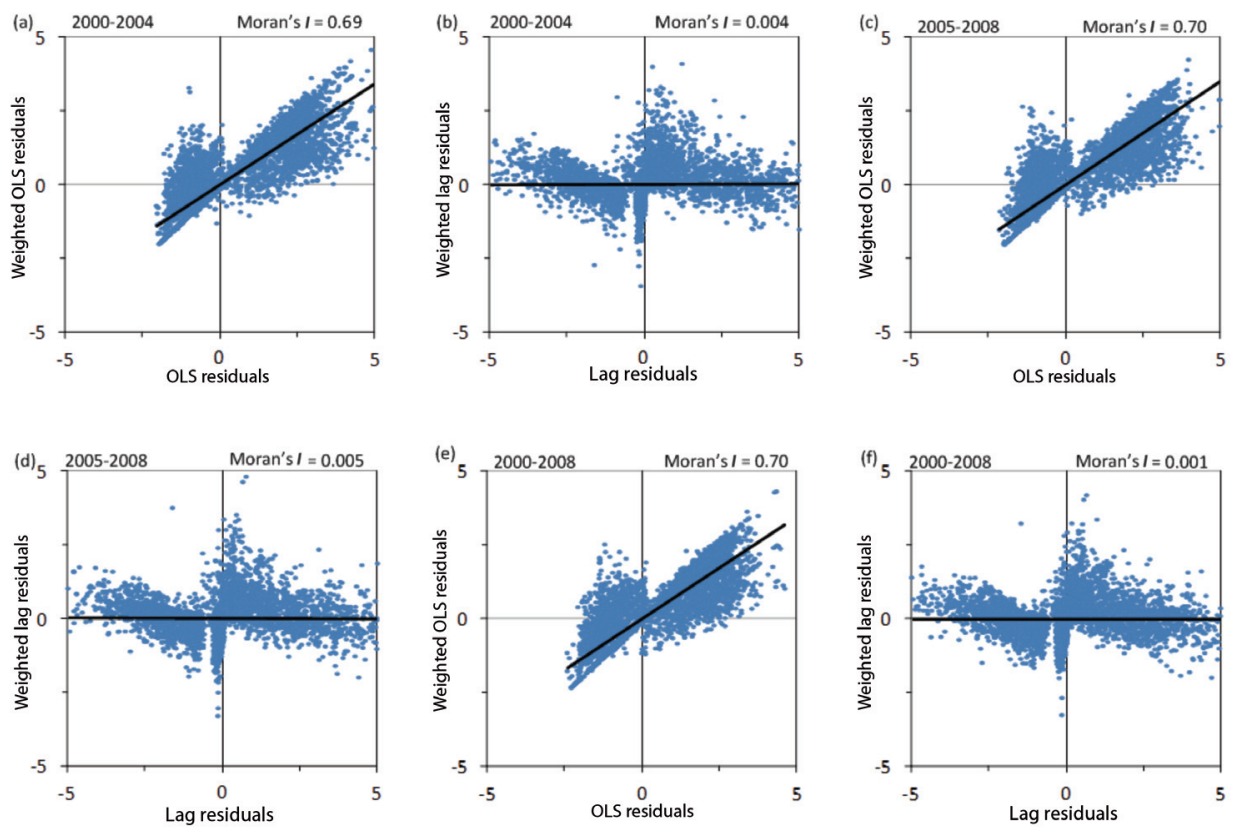

Fig. 3. Moran's I scatter plot for OLS and SLM residuals using the data from coastal areas in Queensland, Australia. 
uated by comparing log-likelihood and Akaike Information Criterion (AIC). Compared to the SLM, the AICs were substantially larger for the OLS models, suggesting an improved fit for the spatial lag specification.

The spatial error model revealed similar results to spatial lag model with similar coefficients (Tables 3 and 4). However, in all our analyses, the spatial lag models better satisfied the regression assumptions compared with the spatial error models. Moreover, the SLMs models had higher $\mathrm{R}^{2}$ and log-likelihood values, as well as lower AIC values than the spatial error models.

\section{Discussion}

This study applied a spatial analytical approach for assessing the association between $\mathrm{BFV}$ incidence rates and the climatic, socioeconomic and ecological factors in Queensland, Australia. Spatial regression analysis has been increasingly used to determine the predictors of mosquito-borne diseases (Wu et al., 2009; Feng et al., 2011; Impoinvil et al., 2011). However, this is the first study to demonstrate the application of spatial regression analysis to BFV transmission.

The results of the study suggest that minimum temperature, rainfall, low tide and distance to coast were potential risk factors for the coastal areas, whereas minimum temperature and rainfall were significant determinants of BFV disease for total area of Queensland. Hence, these variables may be useful for predicting the transmission of BFV disease in Queensland.

Our results support notion that climate variables (such as minimum temperature and rainfall) play an important role in the transmission of BFV disease. Temperature influences the length and efficiency of incubation periods of mosquitoes and the survival of adult mosquitoes (Reeves et al., 1994; Russell, 1995; McMichael, 2003). However, minimum temperature has been found to be the most critical in most regions for the threshold of mosquito survival and development. It has also been reported to lower the feeding rate, therefore reduce the chance for host contact on mosquito, and eventually affect the rate of viral transmission (Russell, 1998b; Gubler et al., 2001). Furthermore, previous research has shown that the extrinsic incubation period and viral development rate can be shortened with higher temperature, through which the greater proportions of mosquitoes becoming infectious at a given time will be expected (Kramer et al., 1983; Turell, 1993; Russell, 1998a; Kay and Jennings, 2002; Mourya et al., 2004).
Our results suggest that minimum rather than maximum temperature plays a significant role in the BFV transmission and these results are consistent with other studies (Tong and $\mathrm{Hu}, 2002$; Hu et al., 2004; Naish et al., 2006; Woodruff et al., 2006; Jacups et al., 2008; Wu et al., 2009). Since some species of mosquitoes are temperature-specific in their breeding (Hardy, 1988; Mackenzie et al., 1994; Russell, 1995), the dominant species of mosquitoes in the study area may be more sensitive to minimum temperature than maximum temperature because the latter changes little in Queensland (a tropical/ sub-tropical state) particularly in summer.

Results of the spatial lag regression models reveal that BFV incidence was significantly and negatively associated with the distance from coast variable. While this is in agreement with previous analyses indicating higher BFV incidences along coastal areas (Naish et al., 2006, 2009, 2011a, 2011b), distance from the coast has not been previously identified as a significant risk factor. Perhaps, those areas which are closer to coast had more BFV cases, more BFV vectors, higher population density and more outdoor activities, on average (Australian Bureau of Statistics, 2011). Moreover, the inverse relationship suggests that as the distance increases towards inlands or away from coastal areas (e.g. $100 \mathrm{~km}$ ) (Naish et al., 2012b), people may be indirectly protected from BFV disease because mosquitoes cannot fly/travel beyond certain distance (Whelan, 1997).

All the coastal models indicate that rainfall and tides were significant risk factors of BFV disease. Previous studies have shown that rainfall and tides have a significant impact on freshwater and salt-marsh mosquitoes, respectively as mosquito development and survival, and breeding habitats depend largely on rainfall and tides (Weinstein, 1997; Lindsay and Mackenzie, 1998; Russell, 1998a; Tong and Wu, 2001; Tong et al., 2004, 2008). Our results suggest that rainfall was positively and significantly associated with BFV disease. Rainfall is one of the important elements for the breeding and development of the mosquitoes (Lindsay et al., 1993; Liehne, 1998). All mosquitoes have aquatic larval and papal stages and therefore require water for breeding (Weinstein, 1997). Considerable evidence has accrued to show that heavy rainfall and flooding can lead to increased mosquito breeding and outbreaks of mosquito-borne diseases in Australia (Lindsay et al., 1993; Tong and Wu, 2001; McMichael et al., 2003). Thus, it could be stated that rainfall may be a strong risk determinant for BFV vectors distribution. Tidal inundation of salt-marshes is a major source of water for breeding of the coastal salt-marsh 
mosquitoes, Ochlerotatus vigilax and O. camptorhyncus. Adult females of these mosquitoes lay their eggs on soil, moist mud and the bases of plants around the margins of their breeding sites. Our results confirm findings from previous research about tidal influence on mosquito-borne disease transmission (Kelly-Hope et al., 2004; Tong et al., 2005; Naish et al., 2006; Dale and Knight, 2008; Jacups et al., 2008; Kurucz et al., 2009). Spatial interaction analysis is not feasible in this study as GeoDa does not incorporate spatial interaction. However, future analysis could use more focused spatial interaction modelling techniques to disentangle these associations.

This study has two key strengths. To our knowledge, this is the first attempt to examine the potential spatial risk factors of BFV transmission, using spatial regression models. Moreover, by focussing on the entire Queensland state (relatively wider geographical area), our analysis considered spatial effects from neighbouring areas, and thus took into account spatial autocorrelation and spatial heterogeneity. Thus, this study has been able to produce more reliable estimates (by considering spatial effects and using spatial models) in determining the relationships between BFV disease and explanatory variables.

There are two major limitations. First, data on other confounding factors such as human immunity, behaviour and travel were unavailable for this study. Additionally, this study did not consider analysing age and gender differences as it was out of the study scope. Second, there could be issues in monitoring and reporting BFV disease notification data and these were discussed in our previous study (Naish et al., 2011a). Moreover, the location of infection site where BFV cases were notified may differ from those where they contracted the disease, particularly during holidays, and misclassification bias is inevitable to some extent. However, this would be very difficult to assess. Hence, qualitative surveys (e.g. interviews) could possibly give some evidences for further research on human behaviour and movement, and transmission dynamics of $\mathrm{BFV}$ disease.

\section{Conclusion}

The study demonstrates that climatic factors, distance to coast and tides are potential risk factors for BFV transmission in Queensland. The spatial, analytical approach used in this study could be applicable to other mosquito-borne diseases. Our study extends the knowledge base for improving BFV disease control and prevention programs in Queensland.

\section{Acknowledgements}

The authors would like to thank the Queensland Health for providing the disease data. $\mathrm{SN}$ is supported by a QUT Award. ST is supported by a NHMRC Fellowship (\#553043) and KM acknowledges funding from the Australian Research Council.

\section{References}

Anselin L, 1998. Spatial econometrics: methods and models. New York: Kluwer Academic Press.

Anselin L, 2004. GeoDa analyst software. The Regents of the University of Illinois, 198-2004.

Anselin L, Bera S, 1998. Spatial autocorrelation in linear regression models with an introduction to spatial econometrics. Boston: Marcel Dekker.

Anselin L, Getis A, 1992. Spatial statistical-analysis and geographic information systems. Ann Regional Sci 26, 19-33.

Anselin L, Syabri I, Kho Y, 2006. GeoDa: an introduction to spatial data analysis. Geogr Anal 38, 5-22.

Australian Bureau of Meteorology, 2011. Data obtained from National Climate Centre, Queensland, Commonwealth of Australia. Available at: www.bom.gov.au/climate/ (accessed on September 2011).

Australian Bureau of Statistics, 2006. socioeconomic indexes for Aeas, Australia. Available at: www.census.abs.gov.au/ ausstats/ (accessed on September 2010).

Australian Bureau of Statistics, 2010. Mesh blocks digital boundaries, Australia. Available at: www.abs.com.au (accessed on August 2011).

Australian Bureau of Statistics, 2011. Census of population and housing - basic community profiles, Commonwealth of Australia, Canberra, ABS. Available at: www.abs.com.au/census (accessed on August 2011).

Bailey TC, Gatrell AC, 1995. Interactive spatial data analysis. Harlow: Longman.

Cliff AD, Ord JK, 1973. Spatial autocorrelation. London: Pion. Dale PER, Knight JM, 2008. Wetlands and mosquiotes: a review. Wetlands Ecol Manage 16, 255-276.

Feng X, Du S, Shu H, 2011. Spatial regression analysis in haemorrhagic fever with renal syndrome (HFRS) in China. IEEE Conference Proceedings, 77-80 pp.

Griffith D, 2006. Effective geographic sample size in the presence of spatial autocorrelation. Ann Assoc Am Geogr 95, 740760.

Gubler DJ, Reiter P, Ebi KL, Yap W, Nasci R, Patz JA, 2001. Climate variability and change in the United States: potential impacts on vector- and rodent-borne diseases. Environ Health Perspect 109, 223-233.

Hardy JL, 1988. Susceptibility and resistance of vector mosquitoes. Boca Raton: CRC Press.

Hu W, Nicholls N, Lindsay M, Dale P, McMichael AJ, 
Mackenzie JS, Tong S, 2004. Development of a predictive model for Ross River virus disease in Brisbane, Australia. Am J Trop Med Hyg 71, 129-137.

Impoinvil DE, Solomon T, Schluter WW, Rayamajhi A, Bichha RP, Shakya G, Caminade C, Baylis M, 2011. The spatial heterogeneity between Japanese encephalitis incidence distribution and environmental variables in Nepal. PLoS One 6, e22192.

Jacups SP, Whelan PI, Markey PG, Cleland SJ, Williamson GJ, Currie BJ, 2008. Predictive indicators for Ross River virus infection in the Darwin area of tropical northern Australia, using long-term mosquito trapping data. Trop Med Int Health 13, 943-952.

Kay BHJ, Jennings CD, 2002. Enhancement or modulation of the vector competence of Ochlerotatus vigilax (Diptera: Culicidae) for Ross River virus by temperature. J Med Entomol 39, 99-105.

Kelly-Hope LA, Purdie DM, Kay BH, 2004. Ross River virus disease in Australia, 1886-1998, with analysis of risk factors associated with outbreaks. J Med Entomol 41, 133-150.

Kramer LD, Hardy JL, Presser SB, 1983. Effect of temperature of extrinsic incubation on the vector competence of Culex tarsalis for western equine encephalomyelitis virus. Am J Trop Med Hyg 32, 1130-1139.

Kurucz N, Whelan PI, Carter JM, Jacups SP, 2009. A geospatial evaluation of Aedes vigilax larval control efforts across a coastal wetland, Northern Territory, Australia. J Vector Ecol 34, 317-323.

Li L, Bian L, Yan G, 2008. A study of the distribution and abundance of the adult malaria vector in western Kenya highlands. Int J Health Geogr 7, 50-61.

Liehne PFS, 1998. Climatic influences on mosquito-borne diseases in Australia. CSIRO.

Lindsay M, Mackenzie J, 1998. Vector-borne diseases and climate change in Australasian region: major concerns and the public health response. Greenpeace.

Lindsay M, Mackenzie JS, Condon R, 1993. Ross River virus outbreaks in Western Australia: epidemiological aspects and the role of environmental factors. In: Health in the greenhouse: the medical and environmental health effects of global climate change. Ewan C (ed): AGPS, Camberra.

Mackenzie JS, Lindsay MD, Coelen RJ, Broom AK, Hall RA, Smith DW, 1994. Arboviruses causing human disease in the Australasian zoogeographic region. Arch Virol 136, 447-467. Mackenzie JS, Lindsay MD, Daniels PW, 2000. The effect of climate on the incidence of vector-borne viral diseases: the potential value of seasonal forecasting. In: Applications of seasonal climate forecasting in Agriculture and Natural Ecosystems. Hammer G, Neville N, Mitchell C (eds). The Netherlands: Kluwer Academic Publishers, 429-452 pp.

MapInfo Professional, 2010. Pitney Bowes Software Inc., New York, USA.
McBride WJH, 2008. Infections in travellers arriving from Australia. Trans R Soc Trop Med Hyg 102, 312-313.

McMichael AJ, 2003. Climate change and human health: risks and responses. Geneva: World Health Organization.

McMichael AJ, Campbell-Lendrum DH, Corvalan CF, Ebi KL, Githeko A, 2003. Climate change and human health: risks and responses. Geneva: World Health Organization.

McMichael AJ, Rosalie EW, Mayer KH, Pizer HF, 2008. Climate change and infectious diseases. San Diego: Academic Press.

Mourya DT, Yadav P, Mishra AC, 2004. Effect of temperature stress on immature stages and susceptibility of Aedes aegypti mosquitoes to chikungunya virus. Am J Trop Med Hyg 70, 346-350.

Naish S, Hu W, Mengersen Ka, Tong S, 2011b. Spatial and temporal clusters of Barmah Forest virus disease in Queensland, Australia. Trop Med Int Health 16, 884-893.

Naish S, Hu W, Mengersen K, Tong S, 2011a. Spatio-temporal patterns of Barmah Forest virus disease in Queensland, Australia. PLoS One 6, e25688.

Naish S, Hu W, Nicholls N, Mackenzie JS, Dale P, McMichael AJ, Tong S, 2009. Socio-environmental predictors of Barmah Forest virus transmission in coastal areas, Queensland, Australia. Trop Med Int Health 14, 247-256.

Naish S, Hu W, Nicholls N, Mackenzie JS, McMichael AJ, Dale P, Tong S, 2006. Weather variability, tides, and Barmah Forest virus disease in the Gladstone region, Australia. Environ Health Perspect 114, 678-683.

Naish S, Mengersen, K, Hu W, Tong S, 2012a. Emerging methods in using GIS to analyse Barmah Forest virus disease in Queensland, Australia. Int J Geoinf 8, 39-44.

Naish S, Mengersen K, Hu W, Tong S, 2012b. Wetlands, climate zones and Barmah Forest virus disease in Queensland, Australia. Trans R Soc Trop Med Hyg 106, 749-755.

Pelecanos AM, Ryan PA, Gatton ML, 2011. Spatial-temporal epidemiological analyses of two sympatric, co-endemic alphaviral diseases in Queensland, Australia. Vector-Borne Zoonot 11, 375-382.

Queensland Department of Transport and Main Roads, 2009. Maritime safety Queensland: tides. Queensland official tidal tables and boating safety guide: tidal notes and definitions. Available at: www.msq.qld.gov.au (accessed on August 2010). Queensland Health, 2009. National notifiable diseases surveillance system, communicable diseaes Australia. Department of Health and Ageing, Australian Government. Available at: http://www.health.gov.au/internet/main/Publishing.nsf/Conten t/cda-cdna-index.htm (accessed on September 2009).

Queensland Health, 2012. Mosquito-borne diseases. Available at: www.health.qld.gov.au (accessed on July 2012).

Queensland Wetlands Programme, 2009. Metadata Wetland Data Version 1.3 - Wetlands. Environmental Preotection Agency, EPA. 
Quinn HE, Gatton ML, Hall G, Young M, Ryan PA, 2005. Analysis of Barmah Forest virus disease activity in Queensland, Australia, 1993-2003: identification of a large, isolated outbreak of disease. J Med Entomol 42, 882-890.

Reeves WC, Hardy JL, Reisen WK, Milby MM, 1994. Potential effect of global warming on mosquito-borne arboviruses. J Med Entomol 31, 323-332.

Rushton G, 1998. Improving the geographic basis of health surveillance using GIS. London: Taylor \& Francis.

Russell RC, 1995. Arboviruses and their vectors in Australia: an update on the ecology and epidemiology of some mosquitoborne arboviruses. Med Vet Entomol 83, 141-158.

Russell RC, 1998a. Mosquito-borne arboviruses in Australia: the current scene and implications of climate change for human health. Int J Parasitol 28, 955-969.

Russell RC, 1998b. Vectors vs humans in Australia - who is on top Down Under? An update on vector-borne disease and research on vectors in Australia. J Vector Ecol 23, 1-46.

Russell RC, 2009. Mosquito-borne disease and climate change in Australia: time for a reality check. Aust J Entomol 48, 1-7.

Tong S, Dale P, Nicholls N, Mackenzie JS, Wolff R, McMichael AJ, 2008. Climate variability, social and environmental factors, and Ross River virus transmission: research development and future research needs. Environ Health Perspect 116, 591-597.

Tong S, Hayes JF, Dale P, 2005. Spatiotemporal variation of notified Barmah Forest virus infections in Queensland, Australia, 1993-2001. Int J Environ Health Res 15, 89-98.

Tong S, Hu W, 2001. Climate variation and incidence of Ross River virus in Cairns, Australia: a time-series analysis. Environ Health Perspect 109, 1271-1273.

Tong S, Hu W, 2002. Different responses of Ross River virus to climate variability between coastline and inland cities in
Queensland, Australia. Occup Environ Med 59, 739-744.

Tong S, Hu W, McMichael AJ, 2004. Climate variability and Ross River virus transmission in Townsville Region, Australia, 1985-1996. Trop Med Int Health 9, 298-304.

Tong S, Hu W, Nicholls N, Dale P, MacKenzie JS, Patz J, McMichael AJ, 2005. Climatic, high tide and vector variables and the transmission of Ross River virus. Int Med J 35, 677680.

Turell MJ, 1993. Effect of environmental temperature on the vector competence of Aedes taeniorhynchus for Rift Valley fever and Venezuelan equine encephalitis viruses. Am J Trop Med Hyg 49, 672-676.

Ward MD, Gleditsch, KS, 2008. Spatial regression model. Thousand Oaks: Sage Publications, Inc.

Weinstein P, 1997. An ecological approach to public health intervention: Ross River virus in Australia. Environ Health Perspect 105, 364-366.

Whelan PI, 1997. Problem mosquito species in the top end of the NT pest and vector status habitats and breeding sites Northern Territory. In: Services DoHaC (ed), Northern Territory.

Woodruff RE, Guest CS, Garner MG, Becker N, Lindsay M, 2006. Early warning of Ross River virus epidemics: combining surveillance data on climate and mosquitoes. Epidemiology 17, 569-575.

Wu PC, Lay JG, Guo HR, Lin CY, Lung SC, Su HJ, 2009. Higher temperature and urbanization affect the spatial patterns of dengue fever transmission in subtropical Taiwan. Sci Total Environ 407, 2224-2233.

Yu DL, Wei YHD, 2008. Spatial data analysis of regional development in Greater Beijing, China, in a GIS environment. Pap Reg Sci Assoc 87, 97-117. 